\title{
Analysis of Flow Field for Automotive Exhaust System Based on Computational Fluid Dynamics
}

\author{
Jianmin $\mathrm{Xu}^{*}$ and Shuiting Zhou
}

School of Mechanical and Automotive Engineering, Xiamen University of Technology, Xiamen 361024, P.R. China

\begin{abstract}
In this study, a double mode muffler that can automatically adjust the exhaust resistance according to the engine speed was designed. Based on computational fluid dynamics theory, the governing equation and turbulent equations for numerical simulation of muffler were established. The pressure loss and the internal flow characteristics of the double mode muffler were analyzed by CFD software. The influence of the distance between the main and submuffler on the flow field of exhaust system was researched. In addition, the internal pressure distribution, the turbulence intensity distribution and the velocity vector diagram of the dual mode muffler were also obtained. The pressure loss of double mode muffler is mainly distributed in the area of air mutations. Main silencer plays a leading role in the entire exhaust system. Therefore, the trend of the pressure loss of the exhaust system with the change in the distance between main and auxiliary muffler was also obtained. When the distance between the main and auxiliary silencer changed from $50 \mathrm{~mm}$ to $300 \mathrm{~mm}$, the pressure loss of exhaust system muffler first increased and then decreased, and following this, continued to increase. The results will provide a theoretical basis for designing complex exhaust system.
\end{abstract}

Keywords: Dual mode muffler, flow distribution, main muffler, pressure loss, vice muffler.

\section{INTRODUCTION}

Muffler could lead to a decline of engine power and economy caused by the exhaust resistance while reducing noise. Therefore, a detailed study on the flow characteristics of the muffler is very important $[1,2]$. For the actual complex muffler, the internal flow is three-dimensional and unsteady. Reports on the distribution of flow field, velocity, pressure and temperature of complex muffler are few. Therefore, it is significant to have numerical simulation on the internal air flow, pressure and temperature distribution of automobile exhaust muffler [3]. Analysis of flowing characteristic of automobile muffler can quickly find unreasonable design of the muffler structure and provide the necessary theoretical support for the optimization design of muffler [4]. The three-dimensional CFD simulation technology is successfully applied in the optimal design of automotive muffler and is bound to open up new ideas and direction to optimize the design of modern exhaust system [5]. Biswas and Mandal [6] studied the effects of structural characteristics of the exhaust muffler on gasoline engine performance in detail. Lota et al. [7] analyzed exhaust back pressure of automobile muffler by using the finite element method. Wang et al. [8] analyzed aerodynamic noise of the perforated pipe muffler. Pangavhane et al. [9] conducted a test and CFD analysis on exhaust back pressure of the perforated pipe muffler. Yasuda et al. [10] predicted the transient acoustic characteristics of the muffler tail pipe based on one-dimensional computational fluid dynamics and conducted the test of transient acoustic characteristics of the

*Address correspondence to this author at the School of Mechanical and automotive Engineering, Xiamen University of Technology, Xiamen, 361024, P.R. China; Tel: 13459263068; E-mail: xujianmin1020@163.com muffler to verify the correctness of the simulation according to the Japanese standard. Lota et al. [11] studied the exhaust back pressure of muffler in detail based on the finite element method and the simulation results were consistent with test results of exhaust back pressure in laboratory. Pangavhane et al. [12] analyzed the exhaust back pressure of perforated muffler based on computational fluid mechanics and studied the impact of muffler perforated pipe on the exhaust back pressure. A muffler with an interconnecting hole on the tail pipe of automobile muffler was proposed to improve its acoustic performance based on the typical structure. Acoustic performances of the muffler were studied in frequency and time domain [13]. Kore et al. [14] analyzed flow field characteristics and acoustic properties of confrontational muffler based on a computational fluid dynamics method. Hui et al. [15] analyzed the distribution of pressure, temperature and renewable noise of complex muffler under unsteady flow conditions according to the basic theory of fluid and acoustic and studied the transmission loss of muffler in steady state. The main factors affecting the silencing effect were found by studying cavity modal characteristics of the acoustic transfer process. Haijun and Zhaoxiang [16] determined the specific parameters of the simple expansion chamber muffler unit using orthogonal experimental design method and measured the flow noise with a self-designed platform. They proposed the parameters of flow distribution based on the analysis of the flow field and established a relationship model of flow noise. Yuan et al. [17] studied the aerodynamic and acoustic performance of motorcycles muffler using the finite element method and test method. Xuezhi and Xizhi [18] conducted the simulation analysis of internal flow field of a single cavity expansion type silencer and revealed the relationship between the pressure loss of muffler and expansion cavity structure and 
entrance velocity. Jianhua et al. [19] studied the impacts of pore size and perforation rate of muffler on perforation pressure based on computational fluid dynamics methods.

A new dual-mode automotive muffler has emerged in recent years. When the engine is running at a low speed, the swept volume is small and the exhaust resistance is not a major problem. Dual-mode muffler can reduce exhaust noise as much as possible. When the engine is running at a high speed, the engine displacement and flow speed will increase. To reduce exhaust resistance, the dual mode muffler can reduce the exhaust resistance as much as possible to obtain maximum engine power output. However, studies on such a dual mode muffler are few. The flow characteristics of dualmode exhaust muffler under low speed and high speed were studied in this paper based on computational fluid dynamics method. The impacts of the distance between the main and sub-muffler on the flow field of entire exhaust system were analyzed. The study provides a theoretical basis for designing complex muffler.

\section{MATHEMATICAL MODEL}

\subsection{Governing Equations}

Under the condition of multidimensional compressible steady flow, the Mass and momentum conservation equation are as follows [20].

$\frac{\partial}{\partial x_{j}}\left(\rho u_{j}\right)=0$

$\frac{\partial}{\partial x_{j}}\left(\rho u_{j} u_{i}-\tau_{i j}\right)=-\frac{\partial p}{\partial x_{i j}}+s_{i}$

where $s_{i}$ is the source term, which represents Catalytic Converter resistance. $\tau_{i j}$ is the stress tensor, for Newtonian flow described as follows:

$\tau_{i j}=2 \mu\left(s_{i j}-\frac{1}{3} \frac{\partial u_{k}}{\partial x_{k}} \delta_{i j}\right)-\bar{\rho} \overline{u_{i}^{\prime} u_{j}^{\prime}}$

where $\mu$ is the molecular dynamic viscosity coefficient; $\delta_{i j}$ is Kroneker number; $\bar{\rho} \overline{u_{i}^{\prime} u_{j}^{\prime}}$ is Reynolds stress tensor. The fluid deformation rate tensor is given by the following formula:

$s_{i j}=\frac{1}{2}\left(\frac{\partial u_{i}}{\partial x_{j}}+\frac{\partial u_{j}}{\partial x_{i}}\right)$

\subsection{Turbulence Model}

Using a standard $k-\varepsilon$ model to calculate the Reynolds stress to solve the flow control equations above [21]:

$$
\begin{aligned}
& \overline{\rho u_{i}^{\prime} u_{j}^{\prime}}= \\
& -2 \mu_{t} s_{i j}+\frac{2}{3}\left(\mu_{t} \frac{\partial u_{k}}{\partial x_{k}}+\rho k\right) \delta_{i j}
\end{aligned}
$$

where $\mu_{t}$ is the turbulent viscosity, given by the following formula:

$\mu_{t}=\frac{c_{\mu} \rho \kappa^{2}}{\varepsilon}$

$k$ and $\varepsilon$ are turbulent kinetic energy and turbulent energy dissipation rate respectively. Their transport equations are:

$$
\begin{aligned}
& \frac{\partial}{\partial x_{j}}\left(\rho \mu_{j} \kappa-\frac{\mu_{e f f}}{\sigma_{\kappa}} \frac{\partial \kappa}{\partial x_{j}}\right)= \\
& \mu_{t} s_{i j} \frac{\partial u_{i}}{\partial x_{j}}-\rho \varepsilon-\frac{2}{3}\left(\mu_{t} \frac{\partial u_{i}}{\partial x_{i}}+\rho \kappa\right) \frac{\partial u_{i}}{\partial x_{i}} \\
& \frac{\partial}{\partial x_{j}}\left(\rho \mu_{j} \varepsilon-\frac{\mu_{e f f}}{\sigma_{\varepsilon}} \frac{\partial \varepsilon}{\partial x_{j}}\right) \\
& =c_{\varepsilon 1} \frac{\varepsilon}{\kappa}\left\{\mu_{t} s_{i j} \frac{\partial u_{i}}{\partial x_{j}}-\frac{2}{3}\left(\mu_{t} \frac{\partial u_{i}}{\partial x_{i}}+\rho \kappa\right) \frac{\partial u_{i}}{\partial x_{i}}\right\} \\
& -c_{\varepsilon 2} \rho \frac{\varepsilon^{2}}{\kappa}+c_{\varepsilon 4} \rho \varepsilon \frac{\partial u_{i}}{\partial x_{i}}
\end{aligned}
$$

In the formula above, $\mu_{\text {eff }}=\mu+\mu_{t}$; The empirical coefficients of $C_{\mu}, \sigma_{k}, \sigma_{\varepsilon}, C_{\varepsilon 1}, C_{\varepsilon 2}$ and $C_{\varepsilon 4}$ are determined according to Table $\mathbf{1}$.

Table 1. Coefficient of experience [11].

\begin{tabular}{|c|c|c|c|c|c|}
\hline$C_{\mu}$ & $\sigma_{k}$ & $\sigma_{\varepsilon}$ & $C_{\varepsilon 1}$ & $C_{\varepsilon^{2}}$ & $C_{\varepsilon^{4}}$ \\
\hline \hline 0.09 & 1.0 & 1.22 & 1.44 & 1.92 & -0.33 \\
\hline
\end{tabular}

\section{FLOW FIELD ANALYSIS OF DUAL-MODE MUFFLER}

\subsection{Design of Dual-Mode Muffler}

In the study, self-regulating dual-mode exhaust muffler was designed. The muffler can automatically adjust the airflow resistance of the exhaust muffler according to the exhaust speed and the engine speed. The three-dimensional model of dual-mode exhaust muffler is shown in Fig. (1). This self-regulation dual-mode exhaust muffler includes: shell, inlet tube D1 (diameter: $50 \mathrm{~mm}$ ), outlet pipe D3 (diameter: $50 \mathrm{~mm}$ ), inner tube D2 (diameter: $15 \mathrm{~mm}$ ) and D4 (diameter: $50 \mathrm{~mm}$ ), springs and valves. The shell is divided into three chambers, which are; the first chamber a, the second chamber $b$ and the third chamber $c$. The spring is located in the intubation D4 (not shown) and is connected to the valve. There are many small holes on the inlet pipe D1 and the diameter of small holes is $8 \mathrm{~mm}$. The valve is closed when the engine is running at a low speed and the exhaust flow rate is low. The airflow flows into the outlet pipe D3 through the small holes of entrance pipe D1 and subsequently discharges into the atmosphere. The airflow direction when the valve is closed is shown in Fig. (1). The muffler has good silencing effect when its exhaust resistance increases. The valve is open because of the impact of airflow 
when the engine is running at a high speed and the exhaust flow rate increases. Some amount of the airflow escapes through the intubation D4 from the third chamber $\mathrm{c}$ to the first chamber a, which can reduce the air flow resistance and reduce the pressure loss of exhaust. The airflow direction when the valve is opened is shown in Fig. (2). The valve aperture increases when the gas flow rate increases. Therefore, according to the engine rotational speed and the speed of the exhaust gas, the exhaust resistance is automatically adjusted to ensure the engine power. After the valve is opened, the air noise generated by the combustion in the tail pipe increases, but the air flow noise generated by friction is reduced. When the engine is running at a high speed, air friction noise is the main component of the tail pipe noise and the overall noise decreases because of smooth airflow.

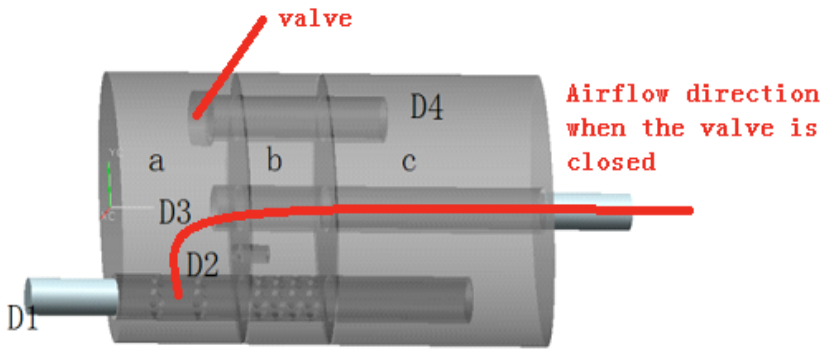

Fig. (1). Three-dimensional model of dual-mode muffler (valve is closed).

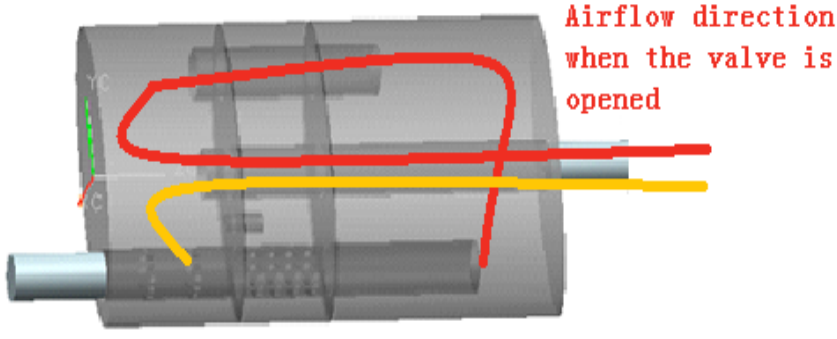

Fig. (2). Three-dimensional model of dual-mode muffler (valve is open).

\subsection{Flow Field Analysis of Dual-mode Muffler}

\subsubsection{Meshing and Boundary Conditions}

The three dimensional model of dual-mode muffler was imported into pre-processing software Gambit in parasolid format. The computational domain was meshed and 370809 grids were obtained. Moreover, the SIMPLEC algorithm was applied for solving the control equation and the standard turbulence $k-\varepsilon$ model was applied for numerical simulation in calculation. The entrance boundary condition was set for velocity entrance while the outlet boundary condition was set for pressure outlet and the pressure value was set to 0 . The other boundary was set for frictionless adiabatic and no-slip wall boundary condition.

\subsubsection{Analysis of Resistance Loss for Double-Mode Muffler}

Fig. (3) shows the pressure distribution of center plane for dual mode muffler when the flow velocity of exhaust gas is $50 \mathrm{~m} / \mathrm{s}$. Pressure loss was obtained by examining the pressure difference between the gas entrance and exit of the muffler. Muffler showed good noise reduction effect, at the same time when the pressure loss of the muffler was small. The big pressure loss has serious impact on the engine power. As can be seen from the Fig. (3) that the pressure of the muffler entrance pipe, the second cavity $b$ and the third cavity c were substantially equal to that of the intubation D4 when the valve was closed. The pressure drop between the Inlet pipe D1 and the first chamber was very large.

Pressure drop is produced mainly because of the mutation loss and the dramatic changes of the airflow direction when the gas flows through the small pores of the intubation D1 and D2. Gas flow cross-section changes drastically when the gas flows into the first chamber from the inlet tube. A pressure loss is produced because of the energy consumption and vortex caused when original gas flow state changes dramatically. The pressure loss is mainly observed in the outlet pipe when the valve is open. Pressure loss is small when the valve is open because the airflow cross-section increases. The dual mode muffler is only suitable for low-speed operation when the valve is closed, otherwise the exhaust pressure will be great. The pressure loss of the muffler observed was 15398pa when the valve was closed and the pressure loss of the muffler was 4802 pascal when the valve was open. The pressure loss when the valve was open was reduced by $69 \%$. The advantage of self-regulating dual-mode muffler is that it can adjust opening angle of valve automatically in order to reduce the pressure loss and increase engine power.

(a) The valve is closed

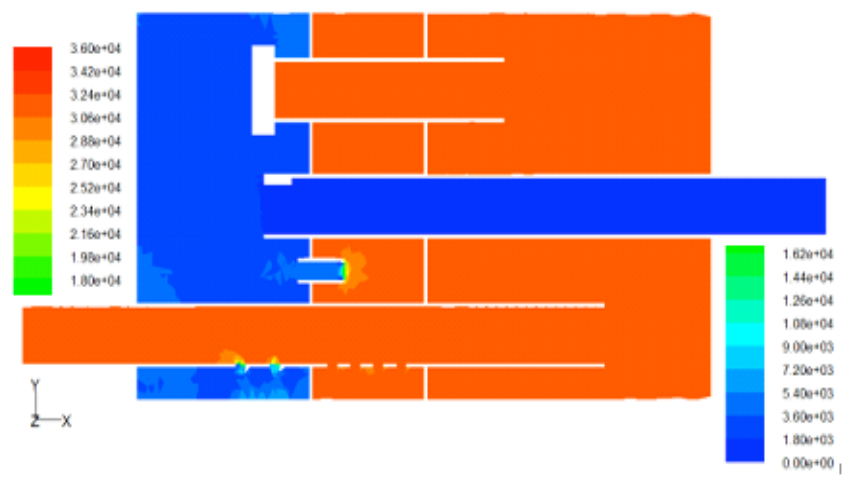

(b) The valve is open

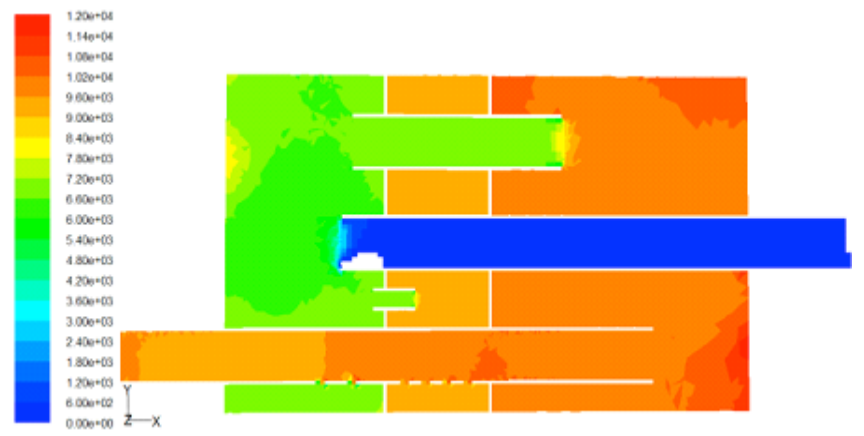

Fig. (3). Pressure contours of center plane of dual mode muffler.

Fig. (4) shows the turbulence intensity distribution of center plane for dual mode muffler when inflow velocity was 
$50 \mathrm{~m} / \mathrm{s}$. It can be seen from the Fig. (4) that the air flow cross-section of the small pores in the inlet tube, the intubation D2 and the left end of the outlet tube changed dramatically when the valve was closed. Airflow turbulence intensity of the region was large and the region was the main energy dissipation area. When the valve was open, the turbulence intensity of the dual mode muffler was found in the left area of outlet pipe. The analysis conclusion on turbulence intensity was generally consistent with the analysis conclusion of the pressure loss.

(a) The valve is closed
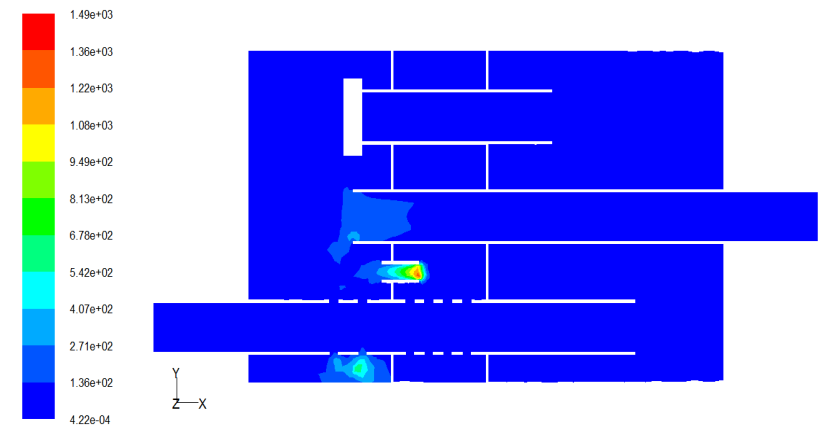

Contours of Turbulent Kinetic Energy $(k)(m 2 / s 2$ Mar 02, 2014
FLUENT 6.3 (3d, pbns, ske)

(b) The valve is open

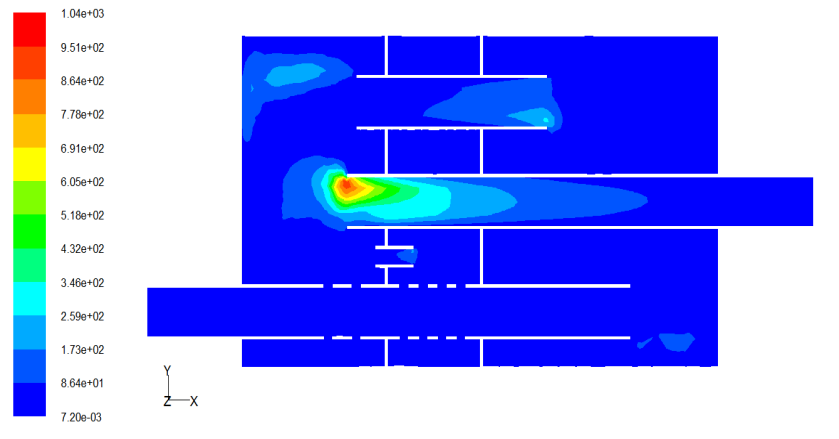

Contours of Turbulent Kinetic Energy (k) (m2/s2) Mar 02, 2014
FLUENT 6.3 (3d, pbns, ske)

Fig. (4). Turbulence intensity contours of center plane for dual mode muffler.

\subsubsection{Internal Gas Flow Characteristics Analysis of Dual- Mode Muffler}

Airflow velocity is the main basis for evaluating the gas regeneration noise of muffler [7]. High airflow rate reduces the attenuation performance of muffler, therefore, it is necessary to analyze the internal flow field of muffler. Fig. (5) shows the velocity contours of muffler central plane when the inflow velocity is $50 \mathrm{~m} / \mathrm{s}$. As can be seen from the Fig. (5), the high-speed airflow zone of dual-mode muffler area is mainly located in the inlet tube, inner tube D2 and outlet tube when the valve is closed. The flow rate in intubation D2 was observed to be the highest while the flow rate of the other peripheral region was relatively low. When the valve is open, the high-speed airflow zone of the muffler area is mainly the inlet pipe, outlet tube and the inner tube D4. The maximum value of air velocity was $92 \mathrm{~m} / \mathrm{s}$, and it was significantly higher than that of the surrounding area. (a) The valve is closed

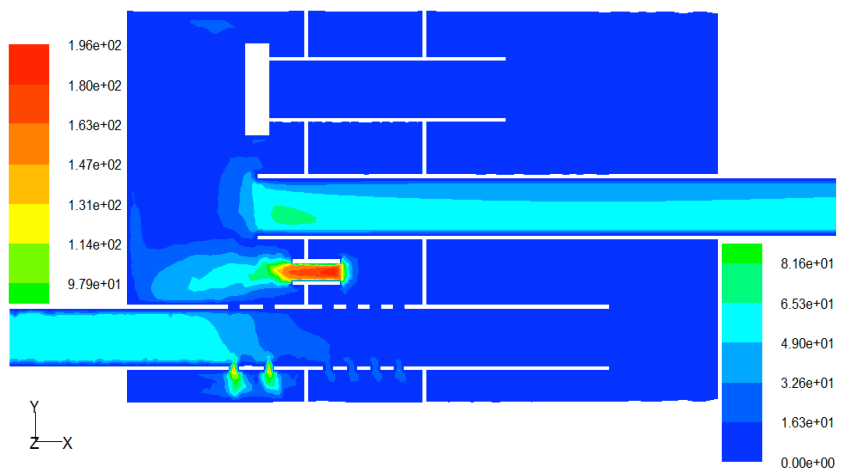

(b) The valve is open

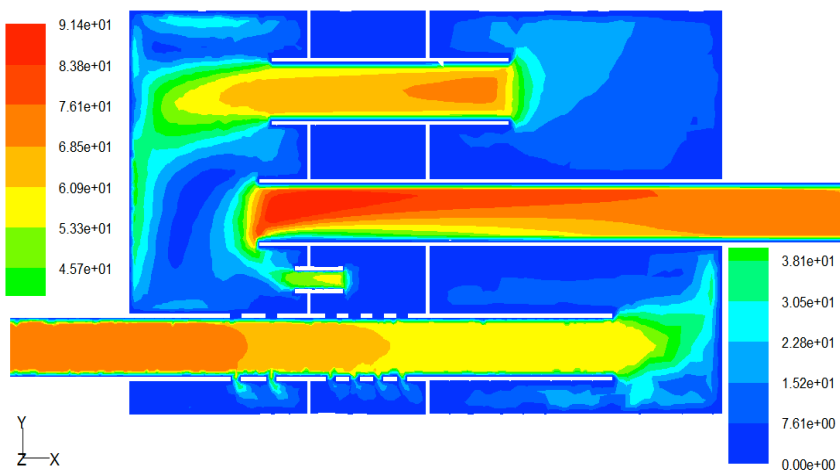

Fig. (5). Velocity contours of of center plane for dual mode muffler.

Fig. (6) shows the center plane velocity vector of dual mode muffler when inflow velocity was $50 \mathrm{~m} / \mathrm{s}$. Some small vortexes appeared in small holes of the inlet pipe and intubation D2 when the valve was closed. Many distinct vortexes appeared in the front end of the outlet pipe and both ends of intubation D2 and D4 when the valve was open. This is the result of high-speed airflow colliding with the wall surface, and the vortex is a major cause of air pressure loss.

\section{IMPACTS OF DISTANCE BETWEEN THE MAIN AND AUXILIARY MUFFLER ON THE FLOW FIELD OF AUTOMOTIVE EXHAUST SYSTEM}

Fig. (7) shows the connection model of primary and secondary muffler, of which the main muffler is a dual-mode muffler and the vice muffler is a perforated muffler. When the distance between the main and sub muffler was $50 \mathrm{~mm}$, $70 \mathrm{~mm}, 150 \mathrm{~mm}, 200 \mathrm{~mm}, 250 \mathrm{~mm}$ and $300 \mathrm{~mm}$ respectively, flow field characteristics of the automotive exhaust system were researched in this paper.

Velocity contours of automobile exhaust system center section when the distance between the main and auxiliary muffler was $150 \mathrm{~mm}, 200 \mathrm{~mm}, 250 \mathrm{~mm}, 300 \mathrm{~mm}$ respectively are shown in Fig. (8). The figure shows that airflow high speed areas of the exhaust system were mainly concentrated in the inlet pipe, the inner tube and the outlet tube of main muffler. The center section velocity contours of automobile exhaust system with 4 kinds of intervals were 
(a) The valve is closed

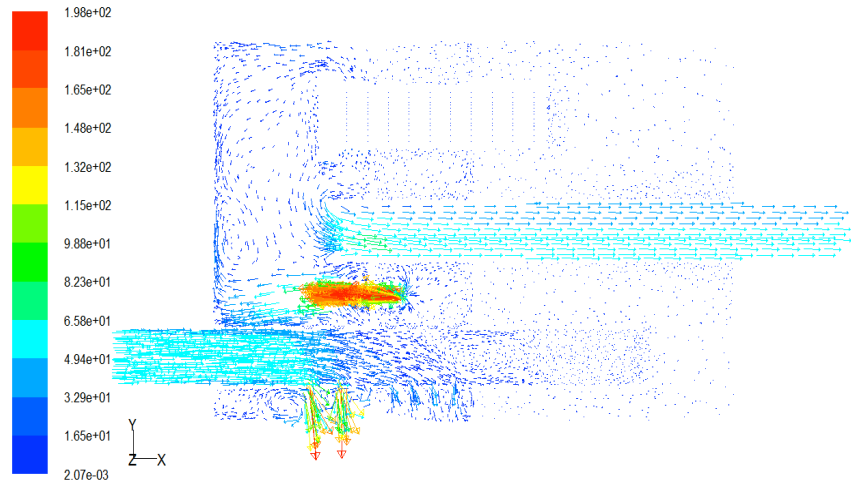

(b) The valve is open

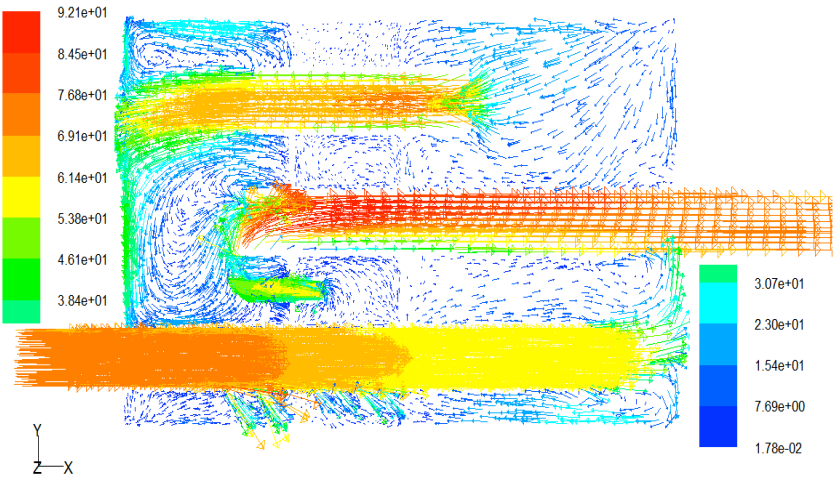

Fig. (6). Velocity vector of dual mode muffler center plane.

basically the same. This indicates that the distance between the main and sub-muffler has no major impacts on the air flow state of the entire exhaust system.

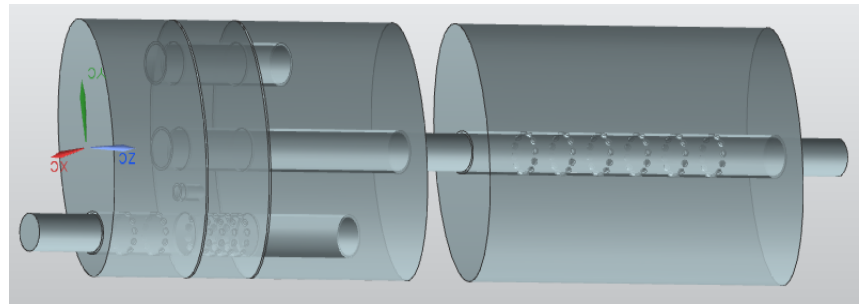

Fig. (7). The connection model of primary and secondary muffler.

Fig. (9) shows the velocity vector contours of the center section for the sub muffler with different distance between primary and secondary muffler. The figure shows that many vortexes were formed around the small pores of perforated pipe inside vice muffler. Vortex can play a role in weakening exhaust energy and silencing effect. When the distance between the main and auxiliary muffler was $150 \mathrm{~mm}, 200$ $\mathrm{mm}, 250 \mathrm{~mm}, 300 \mathrm{~mm}$, the maximum speed of gas flow inside outlet pipe of the auxiliary muffler was $98 \mathrm{~m} / \mathrm{s}$, $96.9 \mathrm{~m} / \mathrm{s}, 96.6 \mathrm{~m} / \mathrm{s}$ and $96.1 \mathrm{~m} / \mathrm{s}$ respectively. This shows that when the distance between the main and auxiliary silencer was $150 \mathrm{~mm}$, the internal airflow of exhaust system was the most smooth and had the minimum flow resistance.

Fig. (10) shows pressure contours of exhaust system when the distance between the main and auxiliary muffler was $150 \mathrm{~mm}$. Fig. (10) shows that the high-pressure zone of exhaust system was mainly inside the main muffler and (a) The distance between the main and auxiliary muffler is $150 \mathrm{~mm}$

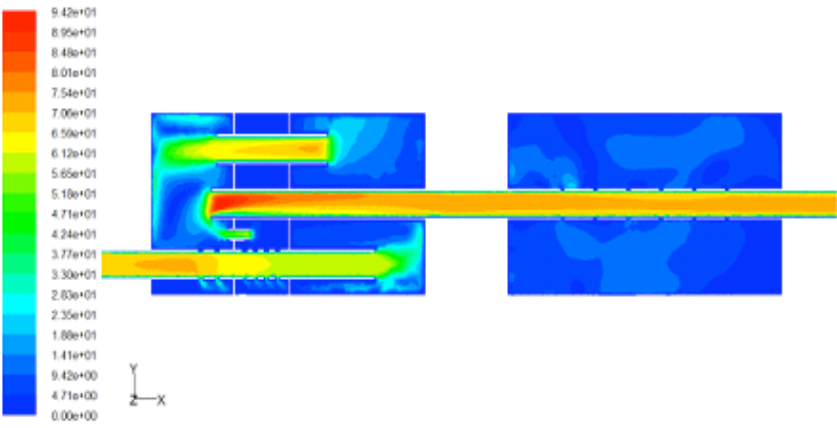

(b) The distance between the main and auxiliary muffler is $200 \mathrm{~mm}$

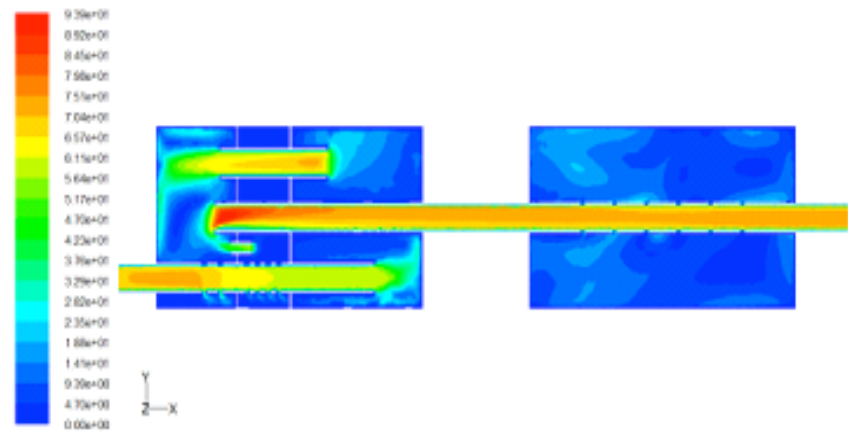

(c) The distance between the main and auxiliary muffler is $250 \mathrm{~mm}$

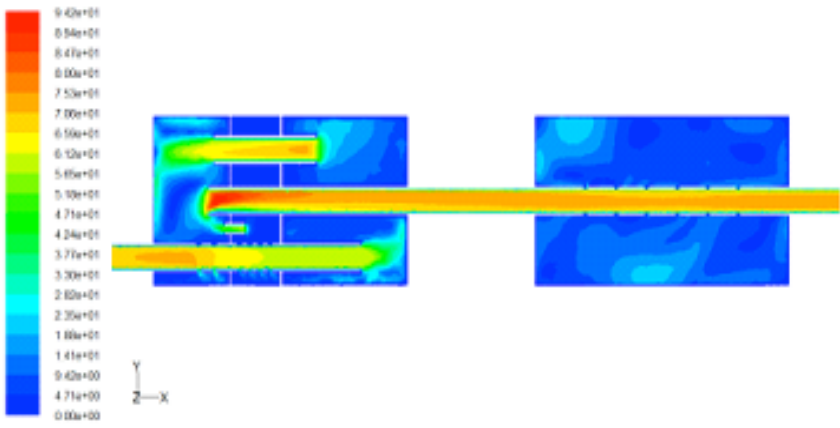

(d) The distance between the main and auxiliary muffler is $300 \mathrm{~mm}$

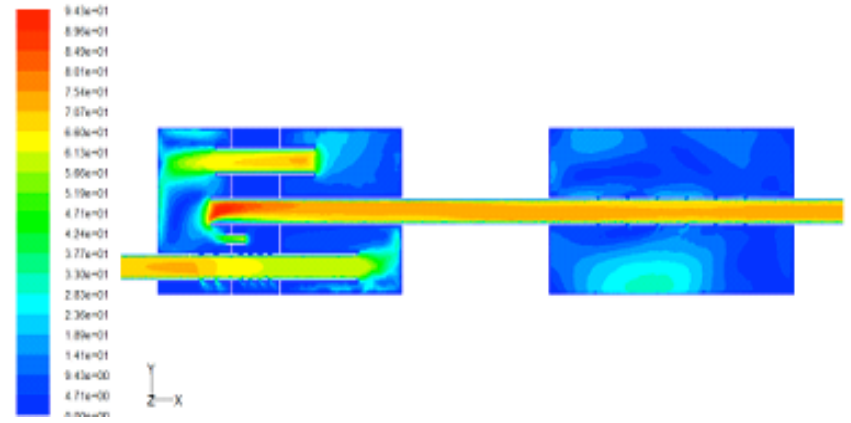

Fig. (8). Velocity contours of automobile exhaust system center section.

vice muffler had a small internal pressure, therefore, the main muffler played a major role in eliminating noise. Fig. (11) shows the impacts of the distance between the main and auxiliary muffler on the pressure loss of automotive exhaust system. The pressure loss of the exhaust system increased sharply when the distance between the main and auxiliary 
(a) The distance between the main and auxiliary muffler is $150 \mathrm{~mm}$
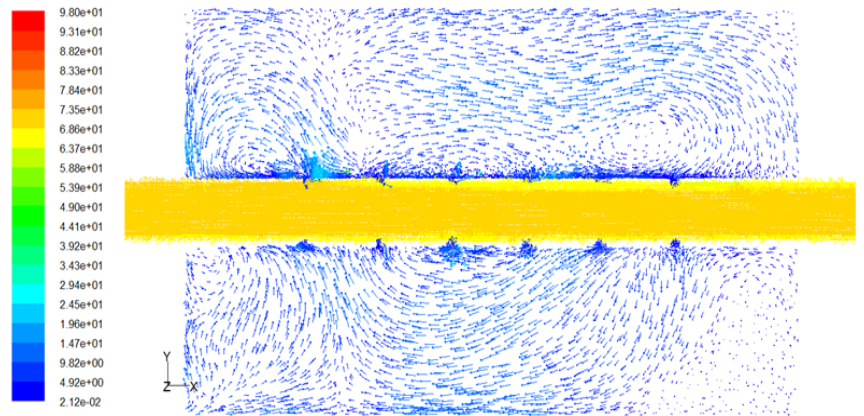

(b) The distance between the main and auxiliary muffler is $200 \mathrm{~mm}$

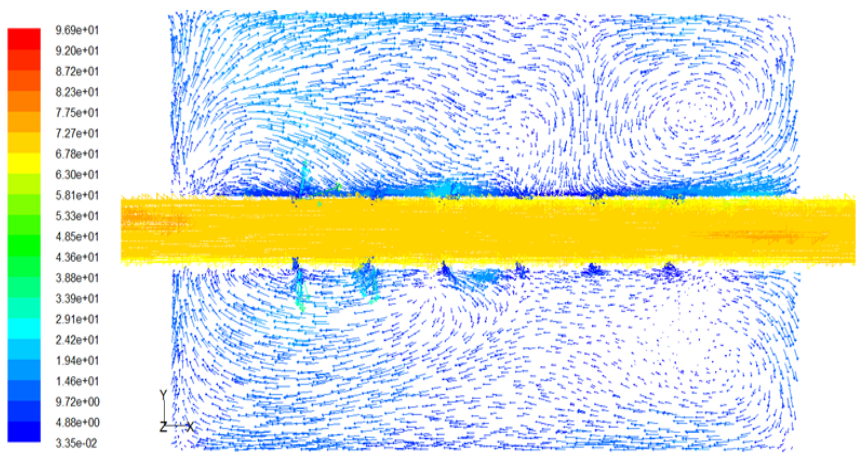

(c) The distance between the main and auxiliary muffler is $250 \mathrm{~mm}$

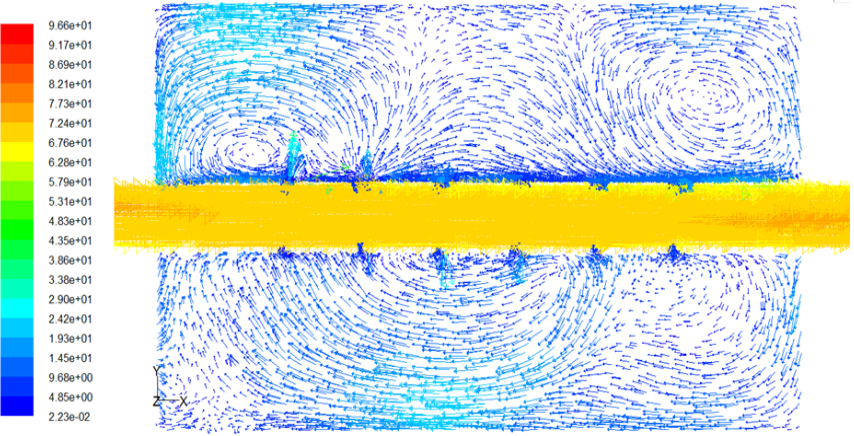

(d) The distance between the main and auxiliary muffler is $300 \mathrm{~mm}$

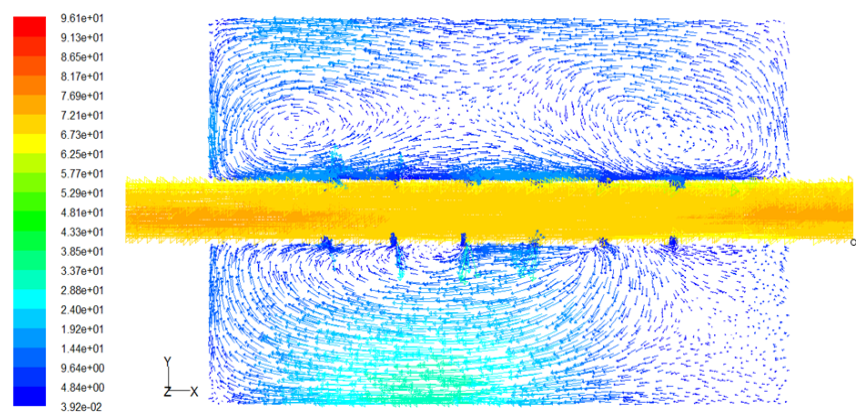

Fig. (9). The velocity vector contours of the center section for the sub muffler.

muffler increased from $50 \mathrm{~mm}$ to $100 \mathrm{~mm}$. The pressure loss of the exhaust system decreased gradually when the distance between the main and auxiliary muffler changed from 100 $\mathrm{mm}$ to $150 \mathrm{~mm}$. The pressure loss of the exhaust system increased when the distance between the main and auxiliary muffler changed from $150 \mathrm{~mm}$ to $300 \mathrm{~mm}$.

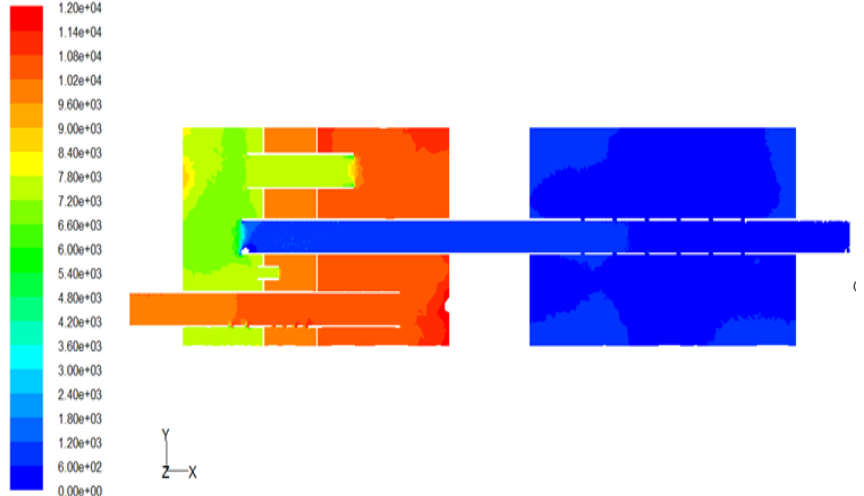

Fig. (10). The pressure contours of exhaust system when the distance between the main and auxiliary muffler is $150 \mathrm{~mm}$.

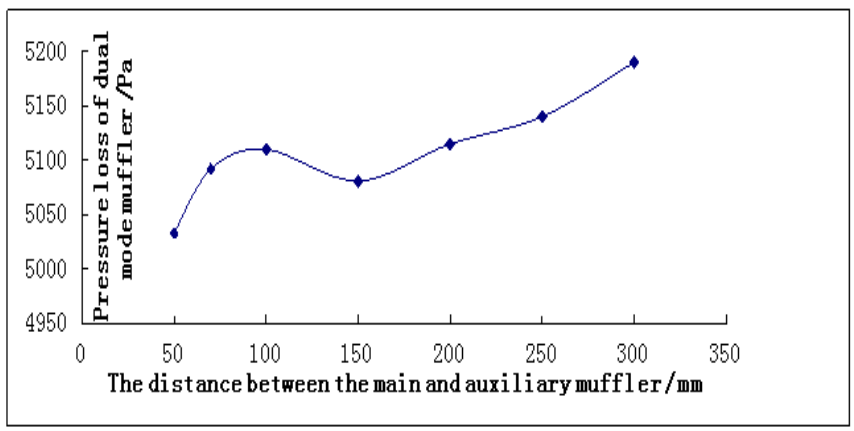

Fig. (11). Variation of the exhaust system pressure loss.

\section{CONCLUSION}

(1) A self-regulating dual-mode exhaust muffler was designed in this paper. The muffler can automatically adjust the resistance of the exhaust muffler according to the engine rotational speed and the speed of the exhaust gas.

(2) The pressure loss of dual-mode mufflers mainly focuses on the area with dramatic changes in the direction of airflow, the area near the perforated pipe of muffler and the area with dramatic changes of flow cross-section. The pressure loss of the muffler with closed valve is four times as big as that of the muffler with opened valve.

(3) The impacts of the distance between the main and auxiliary muffler on the pressure loss of automotive exhaust system were examined. The pressure loss of the exhaust system increased sharply when the distance between the main and auxiliary muffler changed from $50 \mathrm{~mm}$ to $100 \mathrm{~mm}$. The pressure loss of the exhaust system decreased gradually when the distance between the main and auxiliary muffler increased from $100 \mathrm{~mm}$ to $150 \mathrm{~mm}$. In addition, the pressure loss of the exhaust system increased when the distance between the main and auxiliary muffler increased from $150 \mathrm{~mm}$ to $300 \mathrm{~mm}$.

\section{CONFLICT OF INTEREST}

The authors confirm that this article content has no conflict of interest. 


\section{ACKNOWLEDGEMENTS}

This paper was supported by the National Natural Science Foundation of China (Grant No. 51375411; 51205336) and the Natural Science Foundation of Fujian Province (Grant No. 2013J05086).

\section{REFERENCES}

[1] L. Pengfei, and B. Chuanxing, "Numerical analysis of acoustic performance and aerodynamic characteristics of automobile muffler", Noise and Vibration Control, vol. 35, no. 4, pp. 99-102, 2009.

[2] B. Rong, L. Z. Shi, W. Ming, Z. Hu, and Q. G. Yu, "The numerical simulation on acoustic and resistance performance of exhaust muffler", Noise and Vibration Control, vol. 23, no. 1, pp.111-114, 2008.

[3] L. Yinong, L. Ming, Z. Lei, C. Q. Ping, and Z. Ling, "Numerical simulation of the flow and temperature fields in an automotive exhaust muffler", Journal of Chongqing University, vol. 31, no. 10, pp.1094-1097, 2008.

[4] G. Fang, L. B. Tan, and P. Shujie, "Numerical simulation and optimal design for automotive exhaust systems", Automotive Engineering, vol. 29, no. 11, pp. 950-955, 2007.

[5] G. Fang, L. B. Tan, H. Liang, and P. S. Jie, "Structural analyses for the vehicle exhaust system based on CFD simulation", Transactions of CSICE, vol. 25, no. 4, pp. 358-362, 2007.

[6] S. Biswas , and G. Mandal, "An approach to reduce the product variants through design of hybrid muffler for commercial vehicle application", SAE Technical Paper, vol. 15, no. 2, pp.18-20, 2013.

[7] M. S. Lota, V. Ravindran, P. Rao, and R. Verma, "FEA approach for calculating back pressure in automotive muffler", Training, vol. 18 , no. 3, pp. 02-24, 2014

[8] C. N. Wang, C. C. Tse, and S. C. Chen, "Flow induced aerodynamic noise analysis of perforated tube mufflers", Journal of Mechanics, vol. 29, no. 2, pp. 225-231, 2013.

[9] S. D. Pangavhane, A. B. Ubale, V. A. Tandon, and D. R. Pangavhane, "Experimental and CFD analysis of a perforated inner pipe muffler for the prediction of back pressure", International Journal of Engineering \& Technology, vol. 5, no. 5, pp. 115-119, 2013.
[10] T. Yasuda, C. Wu, N. Nakagawa, and K. Nagamurab, "Predictions and experimental studies of the tail pipe noise of an automotive muffler using a one dimensional CFD model", Applied Acoustics, vol. 71, no. 8, pp. 701-707, 2010.

[11] M. S. Lota, V. Ravindran, P. Rao, R. Verma, "FEA approach for calculating back pressure in automotive muffler", Training, vol. 19 no. 4, pp. 2-24, 2013.

[12] S. D. Pangavhane, A. B. Ubale , V. A. Tandon, and D. R. Pangavhane, "Experimental and CFD analysis of a perforated inner pipe muffler for the prediction of back pressure", International Journal of Engineering \& Technology, vol. 5, no. 5, pp. 27-35, 2013.

[13] T. Yasuda, C. Wu, N. Nakagawa, K. Nagamurab, "Studies on an automobile muffler with the acoustic characteristic of low-pass filter and Helmholtz resonator", Applied Acoustics, vol. 74, no. 1, pp. 49-57, 2013

[14] S. Kore, A. Aman, and E. Direbsa, "Performance evaluation of a reactive muffler using CFD”, Zede Journal, vol. 28, no. 1, pp. 8389,2011

[15] J. Xin, T. Zhang, Y. Zhang, C. Ren, "Research of engine exhaust muffler based on finite element analysis of acoustic and unsteady viscous flow", Technology Review, vol. 32, no. 6, pp. 68-74, 2014.

[16] Z. Haijun, and D. Zhaoxiang, "Fluid distribution characteristics of occurring flow regeneration noise from muffler element", Transactions of CSICE, vol. 29, no. 4, pp. 378-383, 2011.

[17] Z. Y. Yuan, S. L. Ming, H. Yansong, and M. X. Dong, "Analysis of whole body noise and muffler improvement for a motorcycle", Vibration and Shock, vol. 30, no. 2, pp. 263-266, 2011.

[18] L. X. Zhi, and H. Xi, "Numerical analysis of single expansion muffler using CFD method", Machine \& Hydraulics, vol. 41, no. 9 , pp. 141-143, 2013.

[19] J. Fang, X.-W. Jiao, X. Tang, L. Wang, P.-G. Jiao, "Pressure loss simulation analysis of straight / cross-flow perforated muffler", Journal of Wuhan University of Technology, vol. 22, no. 10, pp. 28, 2011

[20] S. S. Jin, W. Xin, and Z. R. Juan, "Application of CFD to the Optimal Design of Automotive Catalytic converters", Automotive Engineering, vol. 22, no. 2, pp. 129-133, 2000.

[21] B. Ming, W. C. Cheng, and G. H. Cuo, "Analysis for muffler of 1P68F small gasoline engine", Small Internal Combustion Engine and Motorcycle, vol. 38, no. 3, pp. 68-69, 2009.

(C) Xu and Zhou; Licensee Bentham Open

This is an open access article licensed under the terms of the Creative Commons Attribution Non-Commercial License (http://creativecommons.org/licenses/by-nc/4.0/) which permits unrestricted, non-commercial use, distribution and reproduction in any medium, provided the work is properly cited. 